\title{
Las entidades de la frontera norte y la Agenda 2030: retos para una gobernanza para el desarrollo
}

\section{States on the Northern Border and the 2030 Agenda: Challenges for Governance for Development}

\author{
José María Ramos García \\ Departamento de Estudios de Administración Pública \\ El Colegio de la Frontera Norte, A. C., México \\ ORCID: 0000-0001-6440-6470 \\ ramosjm@colef.mx
}

Resumen: El objetivo de este artículo es analizar el papel de las entidades fronterizas mexicanas con respecto a sus capacidades institucionales en materia de gobernanza del desarrollo para promover políticas públicas según los Objetivos de Desarrollo Sostenible (oDs) de la Agenda 2030. Con ello se examinan algunas implicaciones y desafíos para la implementación de dichas políticas de desarrollo local-regional.

Palabras clave: gobernanza; cooperación; desarrollo; capacidades y transversalidad.

Abstract: The aim of this paper is to analyze the role of Mexican Border States regarding their institutional capacities for development governance to promote public policies based on the Sustainable Development Goals (SDG) of the 2030 Agenda. It examines some of the implications and challenges for the implementation of these local-regional development policies.

Key words: governance; cooperation; development; capacities and transversality.

Fecha de recepción: 12 de mayo de 2016 Fecha de aceptación: 31 de agosto de 2016 


\section{INTRODUCCIÓN}

$E^{1}$ l objetivo de este artículo es analizar el papel de las entidades fronterizas mexicanas con respecto a sus capacidades institucionales en materia de gobernanza del desarrollo local-regional para promover políticas estatales según los Objetivos de Desarrollo Sostenible (oDs) de la Agenda 2030. Con ello se examinan algunas implicaciones y desafíos de la adopción de los oDs en las políticas de desarrollo en la frontera norte mexicana. El argumento central a exponer es que las entidades de la frontera norte han carecido de un enfoque de gobernanza para el desarrollo, lo que explica sus limitaciones para atender la Agenda 21 (1992-2000) y los Objetivos de Desarrollo del Milenio (2000-2015). En este sentido, promover la Agenda 2030 se concibe como un reto para promover una eficaz gobernanza para el desarrollo de dichas entidades mexicanas. La metodología que nos permitió fundamentar el objetivo general consistió en un análisis del marco conceptual de la gobernanza para el desarrollo y sus avances y limitaciones en los gobiernos fronterizos del norte mexicano; un análisis contextual del papel de los estados de la frontera norte mexicana con respecto a la Agenda 21 y a los Objetivos de Desarrollo del Milenio (ODM), procesos en donde se fundamentó una ineficaz aplicación de la gobernanza acorde con sus distintos elementos de gestión (visión, dirección, coordinación, implementación, incentivos, capacitación, evaluación, monitoreo, planeación), y se describieron los principales objetivos de la Agenda 2030, en términos de su importancia e implicaciones para los gobiernos estatales mexicanos, a partir de lo cual se argumentó que con una limitada gobernanza será complejo promover los oDs en los próximos años.

Asimismo, se examinó la relativa relevancia de las agendas internacionales para el desarrollo fronterizo con la prioridad que los gobiernos fronterizos le han concedido a las reuniones de gobernadores fronterizos, de donde se derivan prioridades internacionales y estratégicas para el desarrollo con respecto a prioridades fronterizas o transfronterizas, de escaso impacto para el desarrollo local-regional y, con ello, una limitada gobernanza institucional tanto para el desarrollo como para atender los problemas fronterizos compartidos. Se describió el contexto, objetivos y estrategias planteado por el Programa Regional de Desarrollo del Norte (2014) y sus propuestas de planes de desarrollo estatal, en donde destacamos limitaciones para una implementación eficaz de un enfoque de gobernanza interinstitucional y de los propios gobiernos fronterizos mexicanos, con lo cual se fundamentaron los retos que para las entidades fronterizas implicará promover la Agenda 2030.

\section{()(1) $(2$}


El tema del papel de los gobiernos subnacionales en la cooperación internacional y transfronteriza para el desarrollo es un tema relevante en el campo de las relaciones internacionales. Nuestro argumento es que la construcción de políticas de desarrollo local y regional implica un proceso de gobernanza multinivel. Por lo cual, en la medida en que existe una eficaz cooperación y coordinación interinstitucional, será posible promover los beneficios y reducir los efectos negativos de los procesos de acciones internacionales o transfronterizas. Se asume que la cooperación internacional es una herramienta de la política exterior del país, bajo la cual el ejecutivo federal es el único que tiene facultades para llevarla a cabo, pero también como una herramienta de la acción internacional, en cuyo caso participan diversos actores tanto gubernamentales como no gubernamentales y en distintos ámbitos (Ponce, 2016). Se considera la diversidad de temas, problemas e impactos de la acción internacional que amerita fortalecer una estrategia de gobernanza multinivel para el desarrollo (Morata y Noferini, 2014).

\section{MARCO CONTEXTUAL: GOBERNANZA, AGENDA 21 Y EL DESARROLLO LOCAL FRONTERIZO}

Una de las definiciones de la gobernanza se asocia con un proceso de coordinación entre grupos sociales e instituciones (públicas y privadas), para el logro de objetivos definidos colectivamente, en donde la interacción, las alianzas estratégicas y el cabildeo de los actores desempeñan un papel fundamental (Aguilar, 2010, p. 1). Desde nuestra perspectiva, tal proceso debe ser liderado por el Estado o, en su caso, por las entidades estatales bajo un esquema de una eficaz colaboración interinstitucional para promover el desarrollo. En cambio, el concepto "gobernanza para resultados" (GpR), como tal, es descrito por Caso (2011) como: "la estrategia que usa información del desempeño de las políticas para mejorar la toma de decisiones, que incluye herramientas de planeación estratégica, uso de modelos lógicos, monitoreo y evaluación de los resultados", de tal forma que el modelo organizacional que propone da especial énfasis en los resultados de la gestión y no en los procedimientos como se hacía en otros modelos de gestión de la administración pública. Para el caso de México, es en el año 2000 cuando de manera incipiente inicia la discusión institucional acerca de la importancia de incluir procesos de evaluación de políticas con la finalidad de promover una mayor racionalidad en estas. Es la Secretaría de Hacienda y Crédito Público

\section{()(1) $\$$}


(sHCP) quien promueve los esfuerzos de aplicación del modelo de GpR en la administración pública federal con asesoría de organismos internacionales. A partir de 2007 esta secretaría y el Sistema de Evaluación del Desempeño (SED), así como el Presupuesto basado en Resultados ( $\mathrm{PbR}$ ), componentes de la GpR (Caso, 2011), se adoptan como parte del esfuerzo por superar la pobreza y lograr el desarrollo económico-social del país por medio de la GpR. Sin embargo, este modelo se ha limitado en avances en la formulación e implementación de su dimensión en el presupuesto de resultados. Desde nuestra perspectiva, la principal limitación fue la ausencia de un eficaz acompañamiento del gobierno federal con las entidades estatales y locales bajo una gestión interinstitucional para el desarrollo. Adicionalmente, prevaleció la ausencia del modelo de gobernanza para el desarrollo con todos sus elementos y su vinculación explícita hacia el desarrollo: Visión de una gestión hacia el desarrollo, en donde el modelo de gestión orienta la política de desarrollo; Definición de prioridades, bajo una agenda estratégica de acciones y estrategias focalizadas; Modelo de gestión transversal al desarrollo, con impacto en diferentes dimensiones y en especial en el desarrollo; Fortalecimiento a las capacidades institucionales con distintos actores estratégicos; Liderazgo estratégico para la transversalidad y su impacto en el desarrollo; Coordinación intraorganizacional e interinstitucional para el desarrollo; Coordinación con grupos de la sociedad civil bajo una visión social compartida y acciones focalizadas consensuadas; Estrategias transversales en distintas dimensiones (social, cultural, económica, ambiental y de género); Implementación transversal de políticas para el desarrollo; Monitoreo de las políticas transversales; Incentivos diversos a las mejores prácticas; Evaluación de los impactos del modelo transversal para el desarrollo, identificación de los resultados e impactos sociales de la políticas; Planeación estratégica hacia el desarrollo; Indicadores de gestión con desarrollo humano, determinación de los logros concretos de la implementación de una política integral para el desarrollo. El problema es que generalmente estos elementos de gestión no están presentes en las políticas de desarrollo local y regional fronteriza en el norte mexicano.

El desarrollo sostenible es un tema que ha ido abriéndose paso en las agendas internacionales, nacionales y locales debido a la preocupación general sobre el uso de los recursos naturales. A manera de antecedente, es importante señalar que el concepto de desarrollo sostenible fue introducido, según Otto Brunold (2004), por la Comisión Mundial para el Medio Ambiente y el Desarrollo en el Informe Brundtland de 1987, en el cual se afirmaba que "la humanidad tiene la capacidad de generar un desarrollo sostenible y de asegurar que las

\section{()(1) $(3$}


necesidades del presente sean satisfechas sin poner en riesgo la capacidad de las generaciones futuras, y no poder satisfacer sus propias necesidades" (p. 152). Sin embargo, estos temas no fueron una prioridad para las entidades fronterizas mexicanas, dado que en los años de 1990 a 1995 su prioridad era promover el crecimiento de la industria maquiladora y una mayor vinculación con los procesos de apertura comercial en el marco del Tratado de Libre Comercio de América del Norte (TLCAN). De esa manera, la agenda del desarrollo planteada por la Agenda 21 no fue central para los estados de la frontera norte. En síntesis, se podría afirmar que la Agenda 21 era de gran relevancia, porque no se limitaba al desarrollo económico o al apoyo a la protección del medioambiente, sino que integraba ambos temas y lo social, por medio de una eficaz colaboración entre el gobierno y la participación ciudadana. El problema es que esta gestión asociada en el caso mexicano no fue una experiencia de gobernanza generalizada y acorde a sus distintos componentes de gestión para resultados (visión, dirección, liderazgo, coordinación, incentivos, implementación, capacitación, consensos, monitoreo, evaluación, planeación) (Falcao y Marini, 2010).

\section{LOS OBJETIVOS DE DESARROLLO DEL MILENIO, 2015, LAS REUNIONES DE GOBERNADORES FRONTERIZOS Y EL DESARROLLO SOCIAL FRONTERIZO}

En 2000 se propusieron los ODM, los cuales promovían el desarrollo humano y que fueron acordados por 189 países miembros de la onU con la idea de lograrlos en 2015. Estos objetivos eran: erradicar la pobreza extrema y el hambre; lograr la enseñanza primaria universal; promover la igualdad entre los géneros y la autonomía de la mujer; reducir la mortalidad infantil; mejorar la salud materna, combatir el vir/sida, el paludismo y otras enfermedades; garantizar la sostenibilidad del medioambiente y fomentar una asociación mundial para el desarrollo. Estos objetivos implicaban fortalecer las capacidades institucionales con base de un enfoque intergubernamental, considerando que la mayor parte de los oDM superaban las competencias y capacidades de las entidades estatales mexicanas. En ese contexto, la onu propuso una estrategia general orientada a fortalecer las capacidades de los gobiernos locales, acorde con la propuesta de Capacidad 2015, que pretendía ayudar a los países a desarrollar capacidades para que pudieran integrar los beneficios de la globalización y cumplir o superar los ODM. El impacto de esta agenda de capacidades para el desarrollo local en el caso de las entidades fronterizas

\section{()(1) $(9$}


del norte de México se caracterizó por los siguientes problemas y retos en el lapso de 2000 a 2012. Por un lado, el proceso de integración comercial a través del TLCAN generó desigualdades sociales (Gerber y Anderson, 2015) que impactaron en los niveles de pobreza urbana y en la cohesión social de los municipios fronterizos del norte (Acosta, 2013), lo que aunado a la influencia del narcotráfico, generó violencia, inseguridad y criminalidad en las entidades fronterizas mexicanas (Ramos, 2002). Bajo ese marco, no fue una prioridad la implementación de una agenda interinstitucional para el desarrollo social fronterizo y acorde con los oDM. Un segundo contexto determinante fue el inicio en el año 2001 de la política de seguridad fronteriza de Estados Unidos, que concedió prioridad al fortalecimiento de los controles de seguridad fronteriza con México. Mientras, los gobiernos locales mexicanos seguían concediendo mayor atención a la inseguridad local, cuyos bajos niveles de bienestar repercutían en la incidencia delictiva del fuero común (robos, asaltos y homicidios) (Ramos, 2002). Durante este lapso, la promoción de la cooperación transfronteriza o internacional de parte de las entidades fronterizas del norte de México no se concebía como una prioridad para promover los oDM. Más bien la cooperación transfronteriza se concebía como una alternativa para atender problemas comunes en el marco de las reuniones de gobernadores fronterizos y en particular acorde con los temas de seguridad, educación, desarrollo. Por lo cual, los temas de la Agenda Internacional del Desarrollo no eran su prioridad, lo que refleja una limitada visión de planeación del desarrollo local-regional hacia el 2015. Desde el año 2011 las conferencias de gobernadores fronterizos México-Estados Unidos disminuyeron su prioridad política y como mecanismo estratégico de atención y solución de problemáticas fronterizas. Entre las razones que explican esta limitada prioridad de tales conferencias en los últimos seis años se encuentran las siguientes: el ascenso de sendos gobernadores del Partido Republicano en los estados de Arizona, Texas y Nuevo México; las críticas del anterior gobernador de Texas Dick Perry a México por la inseguridad fronteriza y el flujo ilegal de migrantes; las crisis humanitarias de migrantes que han sido gestionadas de manera parcial desde un enfoque intergubernamental binacional; el desinterés de los gobernadores fronterizos mexicanos por promover una planeación estratégica con sus homólogos fronterizos de Estados Unidos; los beneficios de la integración comercial e industrial liderada por el sector empresarial e industrial bajo el TLCAN; la dificultad estructural de reducir el tráfico de drogas por la importancia del mercado binacional de oferta y demanda $y$, finalmente, que se ha avanzado en un equilibrio entre las prioridades de se-

\section{()(1)(3)}


guridad fronteriza con los cruces fronterizos en el marco de los sucesos de 2001. Por estas razones, para los gobernadores fronterizos mexicanos no ha sido una prioridad articularse a una Agenda de Desarrollo Internacional, lo que se refleja en el hecho de que no existen referencias a la Agenda 21, a los ODM y a los oDs en las reuniones de gobernadores fronterizos. Y, por consiguiente, no existen propuestas de planeación estratégica para articularse a dichas agendas. No obstante, los estados fronterizos se caracterizan por problemas de violencia, inseguridad, crimen organizado y pobreza, a causa de la erosión del tejido social desde los años ochenta y por deficientes políticas de desarrollo social.

En resumen, en el marco de alternancia democrática en el gobierno federal con el arribo del Partido Acción Nacional (PAN) en 2001, no se logró implementar una política efectiva de desarrollo local y regional fronterizo y bajo un esquema de cooperación intergubernamental bajo un modelo de planeación estratégica. Por el contrario, aumentaron los niveles de inseguridad, violencia y criminalidad fronteriza, con lo cual los gobiernos locales concedieron mayor atención a esos problemas, en lugar de promover una agenda hacia el desarrollo. En ese marco, el Programa de Desarrollo Regional Frontera Norte (2001) se desvinculó de la agenda de los ODM (2015), lo que reflejaba la incapacidad de articular la agenda de competitividad -vía crecimiento de la industria maquiladora- con políticas transversales de bienestar (Aguilar, 2009). Durante el periodo de 2006 a 2012 la agenda de seguridad fronteriza generó más tensiones y conflictos a raíz del incremento de la violencia, inseguridad y delincuencia en la frontera con los Estados Unidos (Ribando, Sullivan y Beittel, 2009). Por lo anterior, la consideración de una agenda interinstitucional para promover los oDM no fue una prioridad, dados los problemas de inseguridad fronteriza: en las seis ciudades fronterizas más grandes, con una población aproximada de 5300000 habitantes, el número de homicidios relacionados con el crimen organizado se elevó de 390 (7.3 defunciones por 100000 habitantes) en 2007 a 3585 (67.5 por 100000 habitantes) en 2010 (Pan American Health Organization, 2015).

\section{LA AGENDA 2030: IMPORTANCIA Y RETOS PARA LAS ENTIDADES DE LA FRONTERA NORTE DE MÉXICO}

Esta Agenda 2030 deriva de los ODM que se plantearon en el año 2000, los cuales, como se mencionó, establecían una serie de tópicos importantes

\section{(ㅇ)(1) $(3$}


como son: la reducción de la pobreza, el hambre, enfermedades, desigualdad de género y el acceso al agua y saneamiento (Sanahuja y Tezanos, 2016). Tales objetivos tenían la meta de cumplirse en el año de 2015 y si bien hubo ciertos avances y se mostró la importancia de una agenda unificada, faltó mucho por hacer, especialmente para erradicar la pobreza en el caso de los municipios mexicanos (Acosta, 2013). Los ods son una continuación mejorada de los oDM, que involucra a todos por igual, y busca la mejora de tres ejes: el económico, el social y el medioambiental (Mesa, 2016) (cuadro 1).

Como se puede apreciar, los oDs de la Agenda 2030 son más ambiciosos porque tratan de dar solución a los mayores problemas de la población internacional con un fin claro: la erradicación de la pobreza -cuando los oDM simplemente planteaban su mitigación-. Además, incluyen un fuerte componente medioambiental -con hasta seis objetivos relacionados- que plantea el cuidado del planeta como límite para el desarrollo y la prosperidad económica, y se pone al servicio de la mejora del bienestar y la calidad de vida y la expansión de la libertad. También los oDs son universales, porque pretenden el cambio de paradigma hacia un modelo de desarrollo sostenible social, económica y medioambientalmente, que implica un compromiso universal.

Desde el punto de vista político, es esencial fomentar debates al interior de los países para establecer las posibles direcciones del crecimiento económico; cómo evaluar las inversiones del Estado dirigidas a crear nuevos mercados, y cómo formar nuevos acuerdos entre los sectores público y privado en los que se compartan los riesgos y los beneficios del crecimiento. En otras palabras, se reitera la importancia de promover procesos eficaces de gobernanza para el desarrollo con una perspectiva interinstitucional.

Otro de los retos de una implementación eficaz de la Agenda 2030 es cómo conseguir coinversiones y nuevos tipos de acuerdos entre los sectores público y privado para direccionar el crecimiento económico hacia un modelo inteligente, sostenible e inclusivo.

La implementación de esta agenda para las entidades fronterizas mexicanas implica una diversidad de problemas asociados a la ausencia estructural de un modelo de gobernanza para el desarrollo (Falcao y Marini, 2010), en términos de la importancia que representan los elementos de visión, dirección, capacitación, incentivos, coordinación, planeación, implementación, agendas, evaluación, monitoreo, rediseño. Pero, fundamentalmente, el hecho de que la mayor parte de las metas de los ODM no fueron alcanzadas en el 2015 por las entidades fronterizas mexicanas refleja otro problema central

\section{()(1) $(3$}




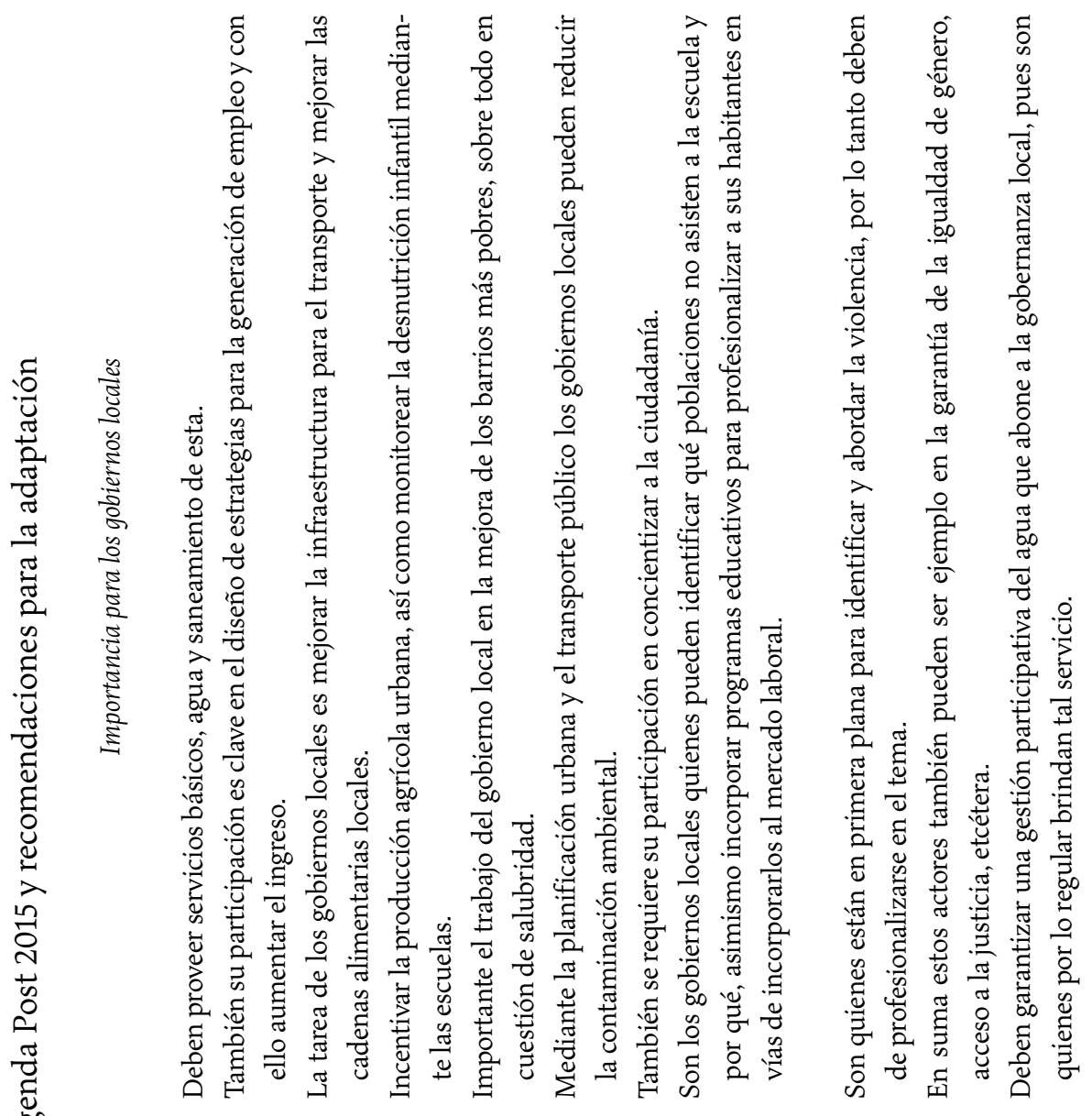

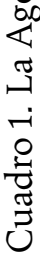
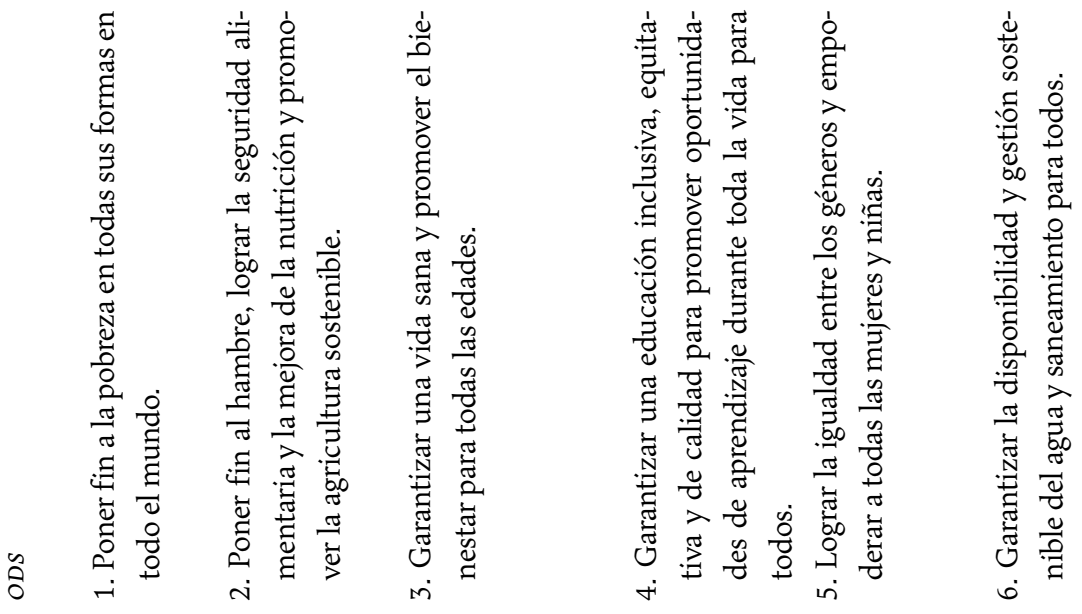

(C) (1) 


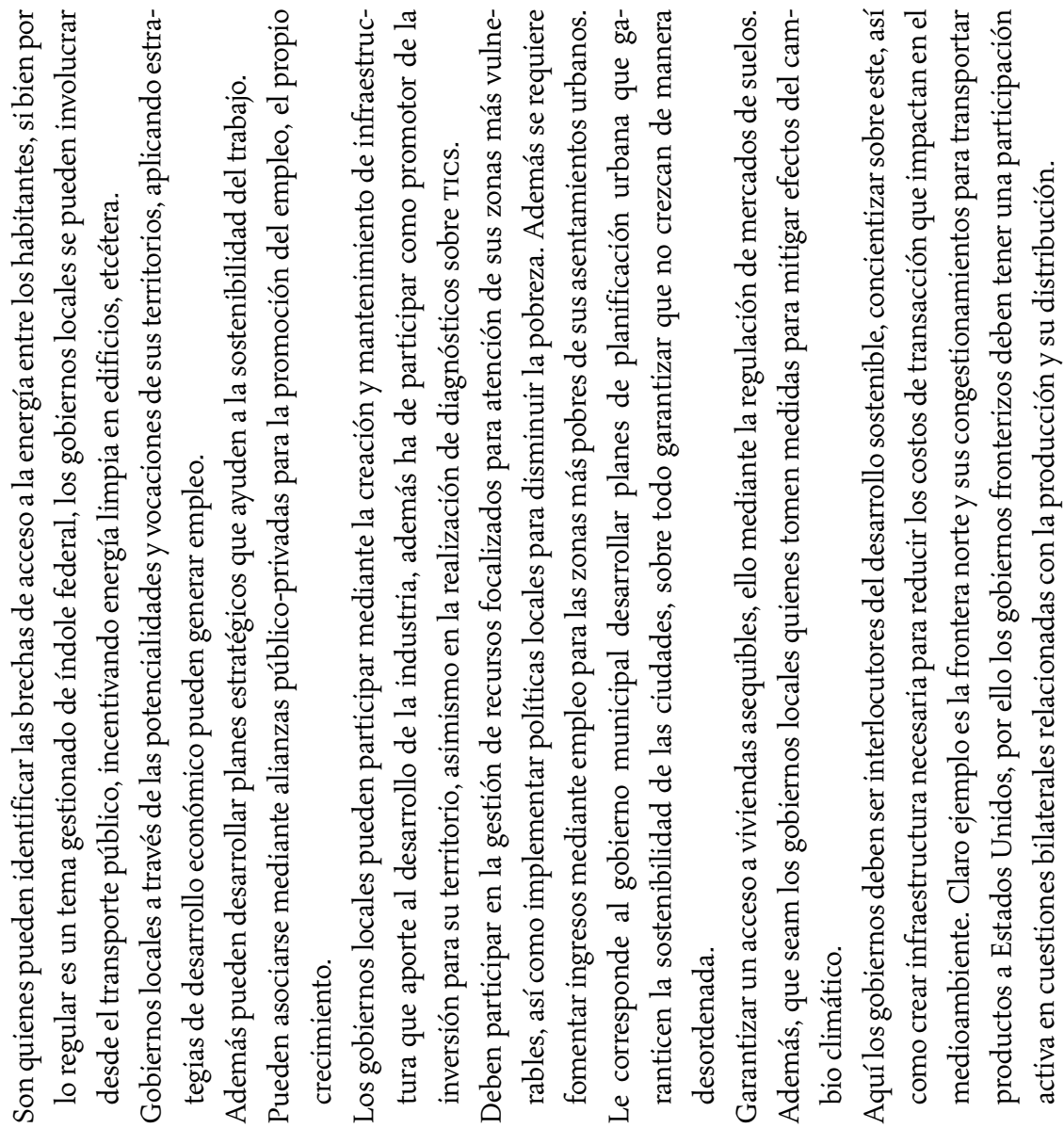

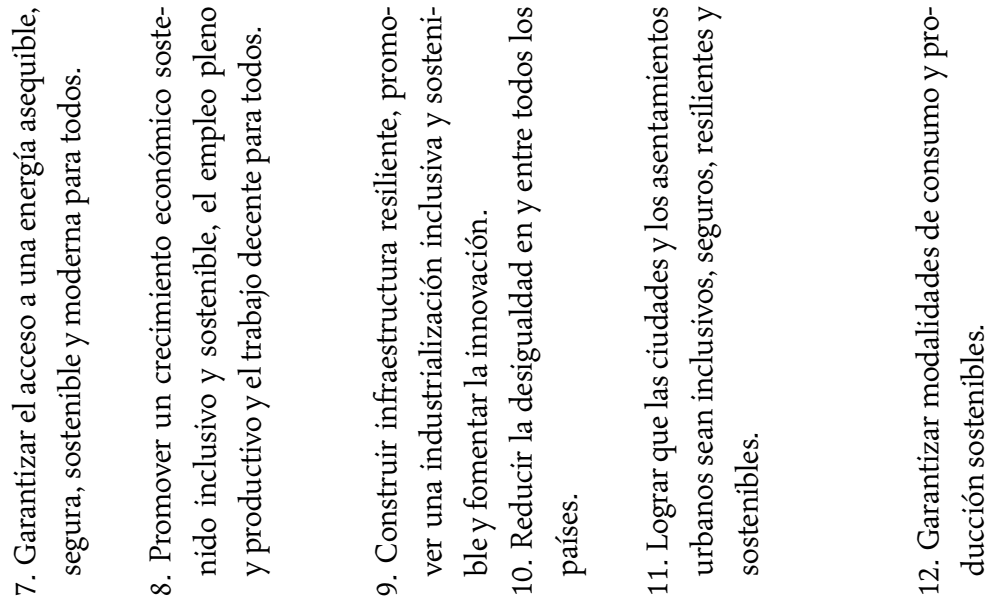

(ㄷ)(1) (8) 


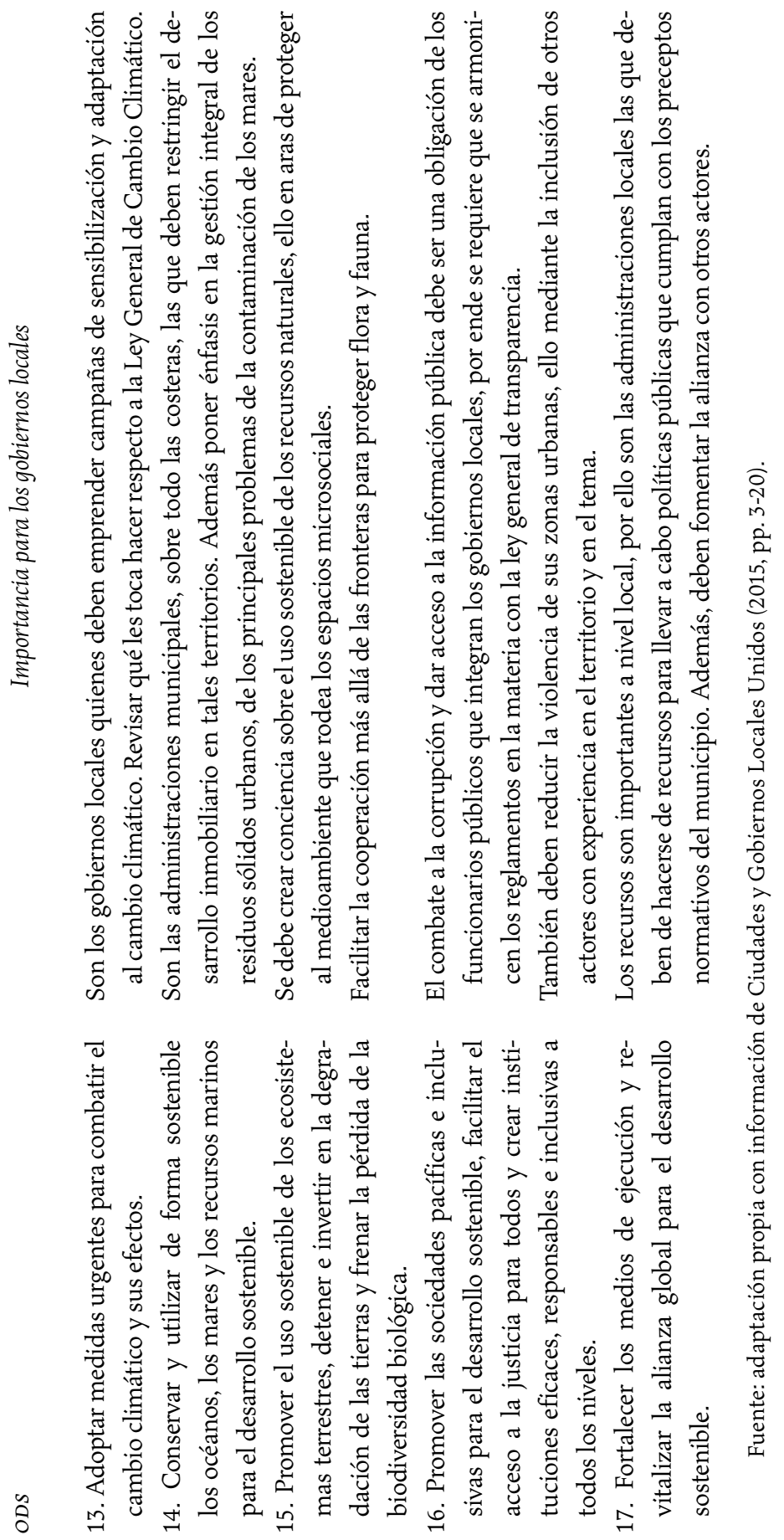

\section{()(1) $(3$}


que puede limitar la implementación de un proceso de planeación estratégico hacia la Agenda 2030 (Mesa, 2016).

Los gobiernos fronterizos del norte de México no tienen una tradición de vincularse hacia agendas internacionales de desarrollo (Ponce, 2016), por lo cual, no han concebido la importancia y el impacto para sus agendas de fomentar estratégias de política internacional y transfronterizas orientadas hacia ese propósito. Sus escasos logros en materia de la gestión de los oDM en el lapso de 2000 a 2015 es un indicador en tal sentido.

La cooperación internacional es una de las herramientas principales para promover las interacciones llevadas a cabo por los gobiernos y entidades fronterizas; sin embargo, para las entidades fronterizas no ha sido una prioridad.

Las reuniones de los gobernadores fronterizos fueron la opción principal de consulta, comunicación e interacción con sus homólogos fronterizos de Estados Unidos; sin embargo, en los últimos cuatro años tales reuniones han disminuido su importancia, en un marco en donde el proceso electoral de noviembre de 2016 en Estados Unidos está generando una discusión en temas de migración, seguridad y procesos de integración comercial.

El apoyo de organismos internacionales para el desarrollo es central, en términos de promover e incentivar la integración de estos objetivos en los planes nacionales de desarrollo de los países, así como del fortalecimiento de las capacidades estadísticas para su medición, potenciar los medios de implementación de la agenda en el continente y fortalecer la arquitectura regional existente. En tal sentido, existe el propósito institucional de la CEPAL de fomentar la creación de arquitecturas interinstitucionales e intersectoriales al más alto nivel para facilitar la implementación y el seguimiento de la Agenda 2030 y la integración de sus tres pilares: económico, social y ambiental.

\section{ALCANCES DE LAS POLÍTICAS DE DESARROLLO DE LA FRONTERA NORTE, EL DIÁLOGO ECONÓMICO DE ALTO NIVEL (DEAN) 2013-2015 Y EL PROGRAMA REGIONAL DE DESARROLLO DEL NORTE, 2014}

A fines de 2012 se generó un cambio en el gobierno federal mexicano, promoviéndose una nueva alternancia. En ese contexto, se plantea el Programa Regional de Desarrollo del Norte (PRDN) (2014) impulsado por la Secretaría de Desarrollo Agrario, Territorial y Urbano (SEDATU, 2014). Este nuevo programa se concebía bajo un enfoque de desarrollo regional-urbano tradi-

\section{()(1) $\circledast$}


cional, dejando de lado un enfoque de gobernanza para el desarrollo bajo una perspectiva de cooperación interinstitucional para el desarrollo. El PRDN propone cinco objetivos generales: impulsar programas que eleven la productividad en la región norte, y sectores de la economía; procurar que la población disfrute de una vida productiva plena; revertir el deterioro ambiental de la región; conducir el ordenamiento urbano, territorial y su infraestructura; promover el fortalecimiento de la infraestructura y servicios de enlace y conectividad regionales (SEDATU, 2014).

La región de la frontera norte comprende un total de 338 municipios y 103916 localidades (equivalen a 14 y 35\% del total nacional, respectivamente), y representan poco más de la mitad del territorio del país (53.5\%), con una superficie continental de $1049122.4 \mathrm{~km}^{2}$. Su población es de 24900000 personas (22.2\% del país) (SEDATU, 2014).

De los 53300000 mexicanos en condiciones de pobreza (extrema o moderada), 8500000 (16\%) habitan en la región norte. Es decir, 32.3\% de los habitantes del norte se encuentran en situación de pobreza, frente a $45.5 \%$ nacional. De los mexicanos que no se encuentran en situación de pobreza, 40700000 padecen alguna carencia social o de ingresos; de estos, 10100000 se ubican en la región norte (25\% del total nacional) (SEDATU, 2014). Estos indicadores generales nos reflejan los rezagos y contrastes en materia de desarrollo social en la región norte del país y plantean el contexto de reorientar las políticas social, urbana, económica, ambiental y de prevención con un enfoque de gobernanza para el desarrollo.

El índice de desarrollo humano revela un nivel relativamente favorable de la región norte respecto al resto del país, destacando particularmente los estados de Nuevo León y Baja California ( 0.79 y 0.77 , respectivamente). No obstante el nivel de bienestar general de la región, aún existe un reto importante en el caso de Durango, y, en menor grado, Sinaloa, Chihuahua y Tamaulipas (SedATU, 2014). La gestión de políticas de competitividad y de bienestar que han caracterizado a estados como Nuevo León y Baja California plantea la necesidad de adaptar dichas experiencias y logros en las entidades de menores avances bajo una gestión interinstitucional para el desarrollo (Oddone, 2016).

Este contexto general nos ofrece elementos para fundamentar los retos de gobernanza y políticas para el desarrollo que implica para las entidades estatales de la frontera norte mexicana avanzar hacia los oDs de la Agenda 2030 (Ponce, 2016). Por ello el PRDN se concibe como una de las opciones para que la región norte pueda avanzar en tal diagnóstico y, con ello, superar los problemas estructurales que la caracterizan y que concebimos como limita-

\section{()(1) $\$$}


ciones para avanzar hacia la Agenda 2030. El PRDN propone dos objetivos generales: por un lado, incrementar la productividad regional, utilizando al máximo el potencial de los recursos ya existentes y aquellos que, por distintos factores, permanecen subutilizados, considerando para ello las vocaciones propias de la región. Un segundo objetivo es el de satisfacer las principales necesidades socioeconómicas de la sociedad en conjunto, haciendo particular énfasis en los sectores que permanecen más rezagados (SEDATU, 2014). Entre las limitaciones en materia de gobernanza y de diseño de políticas que destacamos del programa se pueden mencionar las siguientes:

Las propuestas hacia la frontera norte se conciben de manera aislada o sectorial; la dependencia responsable del PRDN (2014) tiene un enfoque sectorial orientado a una política urbano-regional y que carece de un enfoque de gobernanza y planeación estratégica urbana; no se concibe un enfoque de gestión estratégica hacia el desarrollo fronterizo, con base en las diferentes políticas de transversalidad y de eficaz coordinación que implican los diversos programas que la integran; igualmente no se plantea una perspectiva de gobernanza para la competitividad y el bienestar; el PRDN (2014) carece de un eficaz modelo de gestión interinstitucional y binacional para el desarrollo fronterizo, reproduciendo el mismo problema estructural del anterior Programa de Desarrollo Regional Frontera Norte (2001).

El PRDN tiene el desafío de promover un eficaz fortalecimiento institucional, bajo una efectiva coordinación interinstitucional de las intervenciones y entre múltiples actores. El reto es consolidar una planificación urbana más integral que priorice la inclusión social y productiva, fundamentada con la gobernanza de las ciudades y, al mismo tiempo, encontrar los mecanismos de financiamiento más adecuados y mejorar los sistemas de medición, monitoreo y evaluación del proceso de desarrollo. Estos principios, se considera también, están ausentes en los planes de desarrollo estatal de la frontera norte mexicana.

Estas limitaciones pueden provocar que continúe la tendencia de que los programas de desarrollo local y regional se desvinculen de las agendas internacionales para el desarrollo (Oddone, 2016). De esta manera, el gobierno federal propone un enfoque tradicional de desarrollo urbano-regional, que no establece las bases para que las entidades fronterizas mexicanas avancen hacia los ods de la Agenda 2030.

Con el ascenso de la nueva administración federal en el año 2013, las prioridades del Estado mexicano con respecto a la política de desarrollo se ubican en el marco del Diálogo Económico de Alto Nivel (DEAN) (2013) suscrito por los gobiernos federales de México y Estados Unidos, cuyos objetivos

\section{()(1) $(3$}


generales son: fortalecer la relación económica entre ambos países mediante la promoción de la competitividad y conectividad, el fomento al crecimiento económico, la productividad, la innovación y el fortalecimiento de la alianza bilateral para ejercer un liderazgo regional y global (Secretaría de Relaciones Exteriores $[\mathrm{SRE}], 2016)$. A través del DEAN se define la importancia de la Frontera del Siglo xxi bajo una agenda de competitividad, en donde los problemas del bienestar se conciben como parte de la capacidad del Estado mexicano de articular los avances en la agenda de la competitividad transfronteriza y una eficaz gestión interinstitucional para el desarrollo de la frontera norte (Aguilar, 2009). Sin embargo, el problema estructural es que el DEAN deja pendiente la implementación de una eficaz gobernanza para el bienestar (Gerber y Anderson, 2015) y la reducción de las desigualdades sociales tanto en el ámbito nacional como en el fronterizo (Acosta, 2013). Desde nuestra perspectiva correspondería que estos temas fueran gestionados por el PRDN, los cuales no han sido reducidos aún, como parte de una eficaz política transversal, interinstitucional e integral para el desarrollo fronterizo.

\section{LA ARTICULACIÓN DE LA AGENDA DEL PLAN NACIONAL DE DESARROLLO 2013-2018 Y LOS PLANES DE DESARROLLO ESTATAL: ALGUNOS ELEMENTOS PARA LA AGENDA 2030}

El Plan Nacional de Desarrollo (PND) vigente traza los grandes objetivos de las políticas públicas y las acciones con las que se pretende alcanzar bajo una cooperación interinstitucional. Las principales metas son: México en Paz, México Incluyente, México con Educación de Calidad, México Próspero y México con Responsabilidad Global. Dicho plan, además, impulsa un federalismo articulado, fomentando la sinergia entre regiones, estados y municipios. Y en todas las políticas promueve tres estrategias básicas: democratizar la productividad, consolidar un gobierno cercano y moderno e incorporar la perspectiva de género. Como se puede observar, la Agenda 2030 está muy presente en el PND vigente, e inclusive algunos oDs están explícitamente incluidos en la meta de México con Responsabilidad Global, donde se busca el cumplimiento de dichos objetivos a nivel internacional. Al mencionar esto es importante aclarar que no se excluyen las demás metas de los oDs; por el contrario, se considera que cada una de las metas mencionadas corresponde a dichos objetivos.

\section{()(1) $(9$}


Se considera que el PND vigente en lo conceptual se articula con los objetivos de la Agenda 2030 y con énfasis en la agenda de competitividad y desarrollo. El reto es generar una eficaz vinculación entre el PND, el PRDN, los planes estatales de desarrollo y la Agenda 2030, lo que desde una parte conceptual sí existe. El problema es que se carece de un enfoque de gobernanza de políticas para el desarrollo (Falcao y Marini, 2010) que permita promover una eficaz coordinación entre dichos planes y con una orientación hacia el desarrollo. Además, el desafío es promover una eficaz coordinación de las distintas tareas y acciones que se han planteado las dependencias y entidades federales en sus programas sectoriales y que impactan al desarrollo regional (Ponce, 2016). Desde esta perspectiva, la visión de desarrollo regional requiere de una participación combinada y ordenada bajo una eficaz gestión interinstitucional para el desarrollo.

\section{Planes estatales de desarrollo de las entidades de la frontera norte}

Se incluye esta sección con la finalidad de examinar las propuestas de política estatal de las entidades de la frontera norte y, con ello, analizar los alcances y limitaciones de tales propuestas con respecto a su vinculación con una agenda de desarrollo, en particular con la Agenda 2030, al igual que con el PRDN.

Baja California (2014-2019)

Un aspecto a destacar de la pasada administración estatal de Baja California en el periodo de 2008 a 2009 fue la adopción del modelo de gobernanza para resultados con base de la asistencia del Banco Interamericano de Desarrollo (BID). Es en el año 2010 cuando se inicia la transición de un esquema de administración formal en la estructura gubernamental a nivel estatal a uno basado en lograr resultados. Con este, se buscaban nuevas formas de hacer más con menos; claro ejemplo de ello son la integración a la planeación del Marco Lógico, Costeo de Metas y de disciplina en el ejercicio del gasto público. El gobierno del estado de Baja California concebía a la GpR acorde con los siguientes objetivos:

1. Trabajar en esquemas de presupuestación eficaces y eficientes en el uso de los recursos, que aseguren el cumplimiento de resultados y en sólidos sistemas de seguimiento y evaluación.

\section{()(1) $(3$}


2. Implementarse en la estructura administrativa como modelo de cultura organizacional directiva y de desempeño institucional: énfasis en resultados.

Al implementar el modelo de GpR el gobierno de Baja California pretendía promover una planeación de corto, mediano y largo plazos; gestionar presupuestos por proyecto a ejecutarse y no por techo presupuestal; monitoreo y evaluación de impactos, dejando de lado el clásico monitoreo de actividades, y trabajar bajo un esquema de gobernanza con la inclusión de la sociedad, Congreso ( $\mathrm{y}$ sus diferentes diputados provenientes de diferentes partidos políticos) y otros actores esenciales para el desarrollo de Baja California (INDETEC, 2013). La implementación de la propuesta de GpR en el estado de Baja California estuvo a cargo de la Secretaría de Planeación y Finanzas del estado de Baja California. Su participación presenta los siguientes retos en materia de gobernanza para el desarrollo: renovar un enfoque tradicional de gestión financiera por otro orientado a resultados efectivos; implementar un enfoque del desarrollo en lugar de un enfoque de crecimiento sectorial, pero desvinculado de los ODM; promover sinergias y consensos burocráticos y compartir un enfoque común del desarrollo con dependencias como la de Economía, Desarrollo Social y Seguridad Pública, pero sin considerar los ODM; promover un enfoque común de resultados con la SHCP, destacando la prioridad del crecimiento económico sectorial y no el desarrollo, acorde con los ODM; implementar el enfoque de GpR en el Plan Estatal de Desarrollo con una perspectiva integral y no sectorial y desvinculada de un enfoque del desarrollo.

En el caso actual del Plan Estatal de Desarrollo (PED), es un instrumento que guía a los programas, acciones y recursos de la administración pública de Baja California con respecto al interés general y la búsqueda del bien común. Según el apartado de presentación y visión del plan, está basado en seis estrategias principales: desarrollo humano y sociedad equitativa; sociedad saludable; desarrollo económico sustentable; educación para la vida; infraestructura para la competitividad y el desarrollo; seguridad integral y Estado de derecho, así como un gobierno de resultados y cercano a la gente. La administración del estado de Baja California ha destacado las necesidades de crecimiento y modernización e incorpora el componente de bienestar de la población para lograr efectivos niveles de competitividad y calidad de vida. De manera sincrónica se irán mencionando algunas de las estrategias del plan y su relación con los oDs.

En primer lugar se observa que en la estrategia del desarrollo regional sustentable se puede asociar con el Objetivo 11, que se asocia a lograr que las ciudades y los asentamientos humanos sean inclusivos, seguros, resilien-

\section{(1)(1)}


tes y sostenibles. Otro punto importante del plan es contar con un sistema educativo que se articule con los planes de mejora y que garanticen un sano desarrollo económico y social. Nuevamente se observa que el Objetivo 4 de los oDs está presente, pero ahora con un punto clave a destacar: se busca impulsar el desarrollo económico y social (es decir competitividad y desarrollo) por medio de la educación de calidad.

También se pretende que "la infraestructura sea detonadora de desarrollo económico, social, productivo, competitivo y sostenible, y pueda darse privilegiando los criterios de sustentabilidad como garantía para el bienestar de las generaciones presentes y futuras" (Plan Estatal de Desarrollo de Baja Califormia [2014-2019], p. 7). Esto puede relacionarse con el Objetivo 9, donde se pretende "Construir infraestructuras resilientes, promover la industrialización inclusiva y sostenible y fomentar la innovación”. De nueva cuenta se observa la importancia del eje respecto al desarrollo económico y el bienestar social. También se retoma el Objetivo 16 titulado Paz, justicia e instituciones sólidas, donde se pretende facilitar el acceso de justicia para todos y la creación de instituciones eficaces, responsables e inclusivas. Es de destacar que el actual gobierno estatal pretendió dar continuidad el enfoque de gobernanza para resultados al inicio de la administración. Sin embargo, los avances han sido limitados y la política de desarrollo social se ha caracterizado por un enfoque clientelista, dejando de lado la importancia de una gobernanza con transversalidad para el desarrollo, con lo cual no es una prioridad la vinculación con la Agenda 2030.

SONORA (2016-2021)

El Plan Estatal de Desarrollo 2016-2021 engloba, según su presentación, cuatro ejes estratégicos y dos transversales en la alineación con el PND 2013-2018. Ambos planes conceden a todas las personas el acceso efectivo a sus derechos constitucionales. Al igual que el PND, el plan estatal tiene los siguientes ejes: Sonora en Paz y Tranquilidad, Sonora y Colonias con Calidad de Vida, Economía con Futuro, y Todos los Sonorenses, Todas las Oportunidades.

Como es de suponer, dichos ejes fomentan la justicia, el equilibrio, la productividad y la competencia del Estado, metas que están planteadas en los oDs, y como se trata de una alineación de lo nacional con lo estatal no se procederá a explicar cada uno de los objetivos internacionales con respecto a los del plan estatal sonorense, basta con observar el diagrama 1 sobre la ali-

\section{()(1) $(3$}


neación de dichos planes y consultar lo que ya se mencionó sobre el PND para determinar la articulación.

Dentro del Plan Estatal de Desarrollo de Sonora se hace mención de un punto muy importante respecto a la competitividad:

Sonora se reconocerá en el mundo como un espacio ideal para la inversión y el empleo, por su estabilidad, respeto al Estado de derecho, facilidad para hacer negocios, eficiencia y seguridad de sus vías de comunicación y servicios de logística, infraestructura hidráulica, de telecomunicaciones y de energías renovables, ciudades ordenadas y sustentables, y una sociedad vinculada al conocimiento, comprometida con la solución de problemas globales (Plan Estatal de Desarrollo de Sonora, p. 11)

Es decir, con el plan no sólo se busca lograr un alto grado de competitividad sino que también buscan cooperar para cumplir con los oDs. Este es un aspecto importante que refleja el interés gubernamental de la nueva administración pública de Sonora por posicionar al estado. Desde esta perspectiva es de destacar la nueva concepción que el nuevo gobierno le ha otorgado a la Comisión Sonora-Arizona en los siguientes términos:

Los nuevos tiempos exigen otros esquemas de gobierno y de relaciones no sólo entre las entidades federativas mexicanas, sino que el nuevo orden económico demanda que los estados busquen también en el exterior la solución de sus problemas. En ese contexto, se ha reeditado a la Comisión Sonora-Arizona para tener, a partir de las nuevas relaciones, más profundidad en el trabajo bilateral, de tal suerte que la que tuvo lugar a mediados de junio 2016 en Phoenix, bien podría llamarse una "cumbre" entre los gobernadores de ambos estados, toda vez que en ella participaron, además de empresarios, personalidades de organizaciones privadas, funcionarios de Estados Unidos y tres secretarios de Estado mexicanos, el de SAgarpa, Turismo y Relaciones Exteriores, cuando en todas las anteriores jamás estuvo un representante del Gobierno Federal mexicano. En esta edición se lograron 73 acuerdos en los que se trabajarán en los próximos cinco meses y por primera vez, su cumplimiento y/o seguimiento se revisará en las siguientes sesiones interplenarias para hacer la evaluación general en la próxima Plenaria, a efectuarse en Hermosillo, el 2 de diciembre venidero. ${ }^{1}$

${ }^{1}$ Reeditan comisión Sonora-Arizona. Las5.mx. Periódico Digital, 27 de junio de 2016. Recuperado de http://www.las5.mx/reeditan-comision-sonora-arizona

\section{(ㅇ)(1) $(3$}




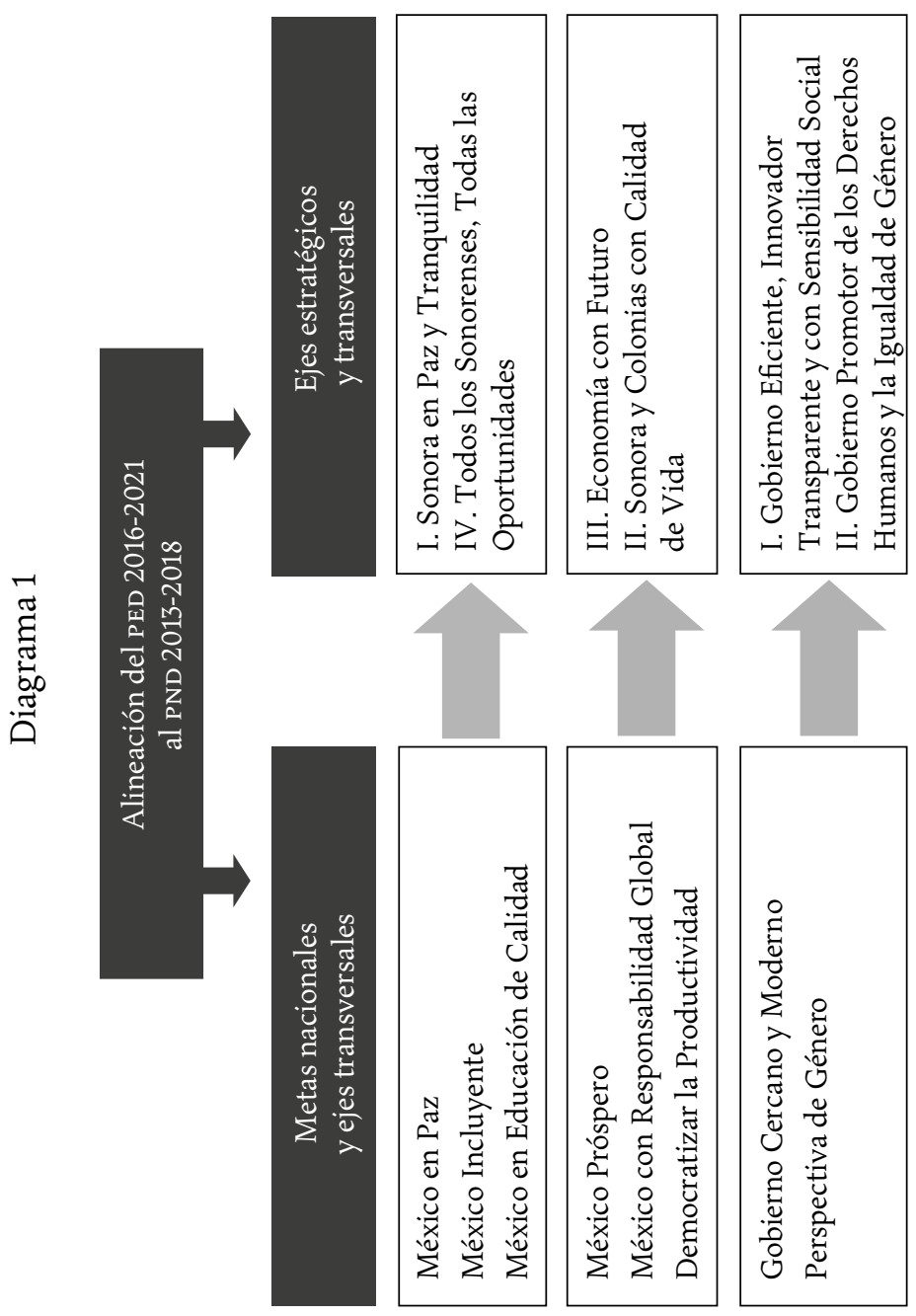

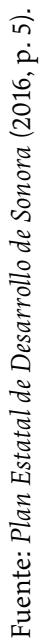

\section{(c) $\$$}


Como se puede apreciar, de manera explícita el gobierno estatal no hace mención a la importancia de los ODM o de los oDs como sus ejes prioritarios. Su prioridad se centra en la Comisión Sonora-Arizona, lo que se refleja en el nuevo enfoque que tiene tal instancia transfronteriza.

\section{Chinuahua 2010-2016}

Al igual que los planes anteriores, este cuenta con cinco ejes principales: Desarrollo Humano y Calidad de Vida; Desarrollo Regional y Competitividad; Formación para la Vida; Medio Ambiente y Sustentabilidad, y Orden Institucional. En el primero de estos, el gobierno estatal se compromete con promover una política de bienestar. En cuanto a Desarrollo Regional, se explica que se "coordinarán los esfuerzos orientados al desarrollo regional en función de las prioridades sectoriales, con orientación estratégica para alcanzar objetivos claros y metas precisas sustentadas en el marco del Sistema Estatal de Planeación".

Asimismo, se retoma, al igual que en los demás planes, los oDs y la cuestión de educación de calidad como clave del desarrollo. También se aborda la preocupación por el medioambiente, pues se introduce en la agenda de gobiernos estatales y, finalmente, en el eje del Orden Institucional es que se suscriben a la seguridad democrática, una gobernabilidad incluyente, combate a la inseguridad, progreso en justicia, etc. Como se puede observar, este plan es compatible con el PND vigente y con los oDs. Uno de los problemas del gobierno del estado es que no fue renovado en el contexto electoral. Entre las propuestas del gobernador electo Javier Corral, está la de que en sus primeros seis meses de gobierno propondrá la creación de una nueva Constitución estatal basada en la transparencia, que incluirá una reforma política a los partidos políticos, una reforma administrativa y redistribución de funciones, competencias para empoderar a la ciudadanía y un sistema de coordinación fiscal para la distribución equitativa de los recursos estatales en los municipios. Uno de los retos que tiene el estado de Chihuahua es el de equilibrar las prioridades del crecimiento de la industria maquiladora con una política integral de bienestar, en la cual se fortalezcan las prioridades en materia de desarrollo. Por igual, la nueva administración tendrá que dar continuidad a las políticas de prevención social como una alternativa a la inseguridad que caracterizó a uno de sus principales municipios como es el de Ciudad Juárez. La problemática de inseguridad y las desigualdades sociales del estado impli-

\section{()(1) $(2$}


can la necesidad de fortalecer los objetivos de la Agenda 2030. Sin embargo, si bien el actual gobierno se vinculó con una agenda internacional para abordar la inseguridad local, tiene el reto al igual que la nueva administración de fortalecer los procesos de planeación estratégica para el desarrollo.

\section{CoAHuila 2011-2017}

El Plan Estatal de Desarrollo de Coahuila estipula, en su presentación, que busca integrar un nuevo proyecto que garantice el crecimiento sostenido y con rumbo al bienestar de su población. Este plan se actualizó acorde con el PND vigente, con el fin de alinear sus acciones respecto a las políticas públicas nacionales. Este plan tiene cuatro ejes rectores: Nuevo Gobierno, Nueva Ruta al Desarrollo Económico, Nueva Propuesta para el Desarrollo Social y Nuevo Pacto Social. Dentro de la visión del plan, se pretende que el estado tenga la capacidad de promover empleo productivo y servicios públicos de calidad. Además, se busca un estado seguro donde se respete la diversidad. Se pretende lograr que Coahuila sea líder en cuanto a bienestar social se refiere, como por ejemplo, en esperanza de vida y condiciones de acceso a la felicidad para todos. A manera de conclusión, se puede identificar que las metas del Plan Estatal de Desarrollo están concatenadas con los objetivos de la Agenda 2030 y por ende con los objetivos del PND vigente.

\section{Nuevo León 2010-2015²}

Según un boletín emitido por el gobierno de Nuevo León (2015), el proceso de consulta para dicho plan inició en enero de ese año y se esperaba que antes del 31 de marzo se concluyera el plazo para hacerlo. Ahora bien, el PED 2010-2015 consta de cuatro ejes principales: Generación de Riqueza; Desarrollo Social y Calidad de Vida; Seguridad Integral, y Gobierno Productivo y de Calidad. Como los mismos nombres de los ejes hacen suponer, se tiene como propósito que el crecimiento económico y el bienestar social analizado en este artículo, ocurran en un entorno sustentable. Con lo anterior, puede decirse que tam-

2 Antes de comenzar este apartado es importante mencionar que se estudiará el Plan Estatal de Desarrollo 2010-2015, debido a que el que corresponde al periodo 2015-2021 aún se encuentra en proceso de elaboración.

\section{(ㄷ)(1) $\$$}


bién están presentes los oDs, específicamente el número 3 que se refiere a la salud y bienestar, el número 8 que habla sobre trabajo decente y crecimiento económico, y el 16 que se asocia a la paz, justicia e instituciones sólidas.

Al igual que el estado de Chihuahua, en julio de 2015 hubo elecciones en Nuevo León y se presentó una nueva alternancia en la gubernatura. Entre las propuestas principales del gobernador electo Jaime Rodríguez, se encuentran las orientadas a promover un Estado de derecho, mayor seguridad y fomento al desarrollo social.

Como se puede apreciar, el actual gobierno propone una agenda social, de cambio institucional y de fortalecimiento del Estado de derecho. Entre sus retos se encuentra el de promover una agenda efectiva hacia el desarrollo, en la cual se equilibren los procesos de competitividad local y regional, con las demandas sociales. Sin embargo, la pasada administración no hizo explícita la relevancia de atender la agenda de los oDM y la actual ha abordado otras prioridades en materia de combate a la corrupción, con lo cual la Agenda 2030 no es una prioridad de la presente administración. Es de destacar que la antepasada administración gubernamental le concedió una relevancia estratégica a la conferencia de gobernadores fronterizos, bajo una propuesta de coordinación interinstitucional tanto nacional como binacional. La prioridad fue fortalecer una agenda de competitividad acorde con la importancia de la economía local, regional e internacional. No obstante, los ODM no fueron su eje central, lo que refleja la prioridad de la agenda fronteriza, en especial con el estado de Texas.

\section{TAMAulipas 2011-2016}

Al igual que el caso de Sonora, este Plan Estatal de Desarrollo afirma su "plena identidad de principios y afinidad absoluta con los objetivos del gobierno del Presidente de la Republica Enrique Peña Nieto". Este plan tiene cuatro ejes rectores: Tamaulipas Seguro; Humano; Competitivo, y Sustentable. Si se analiza el índice del Plan Estatal de Desarrollo de Tamaulipas, fácilmente pueden reconocerse los oDs y más específicamente la relación con competencia y desarrollo. A grandes rasgos se puede mencionar que el PED de Tamaulipas tiene los siguientes aspectos en cada uno de sus ejes:

- Tamaulipas Seguro: instituciones sólidas y confiables; seguridad efectiva para personas y su patrimonio; gobierno humanista, íntegro y de resultados.

\section{()(1) $(9$}


- Tamaulipas Humano: salud humanista; educación integral; desarrollo social participativo; asistencia social y atención a grupos vulnerables.

- Tamaulipas Competitivo: productividad y competitividad; atracción de inversiones y generación de empleos; infraestructura y financiamiento para el desarrollo; economía dinámica.

- Tamaulipas Sustentable: desarrollo planificado de las ciudades; servicios públicos de calidad; aprovechamiento sustentable del agua; medioambiente sustentable.

Como se puede ver, el programa estatal está alineado al PND actual, al igual con respecto a los oDs y, sobre todo, promueve la competitividad y el desarrollo. Sin embargo, al igual que la mayor parte de los estados de la frontera norte, la vinculación con los ODM no ha sido una prioridad estratégica, porque no forma parte de su propuesta de manera explícita. Además, el estado de Tamaulipas se sigue caracterizando por un contexto de inseguridad, que genera problemas de gobernabilidad. De ahí que en julio pasado (2016) se haya dado una alternancia en el gobierno estatal, lo que también se concibe como otro problema para la continuidad cuando existen iniciativas de cooperación internacional exitosas.

Resumiendo: la mayor parte de los estados de la frontera norte han adaptado sus planes estatales de desarrollo acorde con las prioridades nacionales en materia de desarrollo. Sin embargo, entre los problemas a destacar se pueden mencionar los siguientes: la mayor parte de los estados de la frontera norte tienen problemas de gobernabilidad, lo que refleja la dificultad de conciliar los temas políticos con los procesos de planeación para el desarrollo; la calidad y pertinencia en términos de gestión y de políticas de dichos programas pueden limitar una implementación eficaz; no se plantean estrategias viables para promover una agenda transversal para el desarrollo; por igual, son incipientes los procesos de gobernanza multinivel y social, con lo cual en la mayor parte de los casos no existen agendas estratégicas para el desarrollo y consensuadas con los distintos actores (Oddone, 2016). Si bien los programas estatales se asocian tanto a los oDM como a los oDs no se plantea un modelo de gobernanza para promover una estrategia de vinculación (Ponce, 2016). La mayor parte de los municipios cuenta con áreas de asuntos internacionales o fronterizos, pero carecen de una eficaz agenda que permita articular los procesos de competitividad y bienestar bajo un enfoque de coordinación interinstitucional. El hecho de que la mayor parte de los gobernadores fronterizos (Texas, Arizona y Nuevo México) sean del Partido Republicano, condiciona avanzar en agendas estratégicas. El contexto elec-

\section{()(1) $(3$}


toral de Estados Unidos puede hacer más complejo abordar los problemas fronterizos con las contrapartes fronterizas estadunidenses. No obstante, el hecho de que los estados fronterizos confronten problemas, pero también oportunidades para alcanzar los oDs, según las capacidades institucionales, tanto estatales como locales, implica una serie de procesos de adaptación, acorde con sus problemas, capacidades, metas y prioridades para el fomento al desarrollo en los próximos años.

\section{CONCLUSIONES GENERALES}

El objetivo de este artículo fue analizar el papel de las entidades fronterizas mexicanas con respecto a sus capacidades institucionales en materia de gobernanza del desarrollo para promover los oDs de la Agenda 2030. Con tal análisis se plantearon algunas implicaciones y desafíos en las políticas de desarrollo local-regional. Se fundamentó el argumento de que la mayor parte de esos estados de la frontera norte no han fortalecido sus capacidades en el contexto de las Agendas 21 y 2015, lo cual dificultará su posicionamiento para avanzar hacia los oDs de la Agenda 2030. Esta situación ha sucedido a causa de que la mayor parte de los estados fronterizos mexicanos no ha concedido relevancia a promover sus capacidades de gobernanza para promover el desarrollo local acorde con las prioridades de tales agendas internacionales (Ponce, 2016). Un segundo factor es la influencia de la inseguridad, violencia y criminalidad que condicionó las agendas locales a los temas de seguridad (Ramos, 2002), dejando de lado una agenda para el bienestar (Acosta, 2013); la importancia concedida al fomento de la industria maquiladora y como alternativa para atender problemas de desempleo, inversión, competitividad, lo que determinó marginar políticas complementarias para promover el desarrollo local (Aguilar, 2009). En ese marco, el avance de los gobiernos estatales fronterizos para promover los objetivos de la Agenda 2030 implica adoptar decisiones políticas y capacidades locales para promover una eficaz gobernanza estratégica para el desarrollo (Falcao y Marini, 2010). Si bien se ha planteado un Programa de Desarrollo Fronterizo (2014) que pretende promover la competitividad y el desarrollo local, se considera que las estrategias tienen limitaciones de gestión y de políticas eficaces de coordinación interinstitucional, por lo cual sus logros no han sido tales a dos años de su implementación.

\section{()(1) $\$$}




\section{LISTA DE REFERENCIAS}

Aguilar, I. (2009). Desafíos de la política de desarrollo regional en México. En J. Ramos e I. Aguilar (coords.), La gestión del desarrollo local en México: Problemas y agenda (p. 41-74). México: El Colegio de la Frontera Norte/Miguel Ángel Porrúa.

Aguilar, L. F. (2010). Gobernanza y cooperación transfronteriza. Ponencia presentada en el seminario Relaciones México-Estados Unidos: De la Interdependencia, la Integración Económica a la Corresponsabilidad en Seguridad Fronteriza. El Colegio de la Frontera Norte, Tijuana, B. C.

Acosta, F. (2013). Hacia una política social transversal en el municipio de Tijuana. En J. Ramos y A. Villalobos (coords.), Gobernanza y prevención transversal en la frontera norte de México (pp. 117-155). Mexicali, B. C.: Centro de Alta Dirección Pública/ Instituto Universitario y de Investigación Ortega y Gasset/Colectivo de Análisis de la Seguridad con Democracia.

Caso, A. (2011). El presupuesto en base a resultados y el sistema de evaluación de desempeño en México: una propuesta para entidades federativas. En M. Ramos, J. Sosa y F. Acosta (coords.), Evaluación de políticas públicas en México. México: El Colegio de la Frontera Norte/Instituto Nacional de Administración Pública.

Ciudades y Gobiernos Locales Unidos (2015). Objetivos del Desarrollo Sostenible. Lo que los gobiernos locales deben saber. Recuperado de http://observ-ocd.org/es/ objetivos-de-desarrollo-sostenible-lo-que-los-gobiernos-locales-deben-saber

Falcao, H. y Marini, C. (2010). Una guía de gobernanza para resultados en la administración pública. Brasil: Instituto Publix.

Gerber, J., y Anderson, J. (2015). Twenty years of NAFTA: Are the measures of human development converging and the border? En R. Barajas et al., Fronteras y procesos de integración regional (pp. 133-150). México: El Colegio de la Frontera Norte/CIAD/ Juan Pablos Editor.

Gobierno del Estado de Nuevo León (17 de diciembre, 2015). Boletín. Ciudadaniza estado Plan Estatal de Desarrollo. Recuperado de http://www.nl.gob.mx/noticias/ ciudadaniza-estado-plan-estatal-de-desarrollo

INDETEC (2013). La gestión para resultados en Baja California 2007-2013. Seminario Internacional de Gestión para Resultados. Recuperado de: http://www.indetec.gob. $\mathrm{mx} /$ Eventos/Cepal2013/IX/materiales/Lun13_05_Grp_Baja_California_2013.pdf

Mesa, M. (2016). El ods 16: Paz, seguridad y gobernanza. Sistema Digital. Recuperado de http://www.fundacionsistema.com/temas-253-sobre-del-milenio-a-la-sostenibilidad-la-nueva-agenda-global-de-objetivos-de-desarrollo-sostenible/

Morata, F. y Noferini, A. (2014). Gobernanza y capacidades institucionales en la frontera pirenaica. WP 326. Institut de Ciències Polítiques i Socials (ICPS).

\section{()ㅜ(1) $\$$}


Recuperado de http://www.academia.edu/6735116/Morata_F._y_Noferini._A_ 2014_._Gobernanza_y_capacidades_institucionales_en_la_frontera_pirenaica _-_WP_326._Institut_de_Ci\%C3\%A8ncies_Pol\%C3\%ADtiques_i_Socials_ICPS_ Oddone, N. (26 de abril, 2016). Opciones de cooperación transfronteriza de los municipios mexicanos en la frontera sur y la Agenda 2030. Ponencia presentada en el seminario Gobernanza en las Fronteras de México: Hacia la Agenda 2030: Dilemas para las Capacidades Institucionales Locales, El Colegio de la Frontera, México, D. F.

Otto Brunold, A. (2004). La Agenda 21 y las perspectivas de cooperación Norte-Sur: El principio del desarrollo sostenible. Cuadernos del CLAEH, 88, 151-160. Montevideo. Recuperado de http://148.231.10.114:3018/ehost/pdfviewer/pdfviewer?sid=4b 161086-7306-4afc-b080-cd21857a98e8\%40sessionmgr102\&vid=1\&hid=102

Pan American Health Organization (2015). Recuperado de http://www.paho.org/sa ludenlasamericas/index.php?id=63:united-statesmexico-bordrarea\&option=com _content

Plan Estatal de Desarrollo de Baja California (2014-2019). Visión de Desarrollo. Recuperado de http://www.bajacalifornia.gob.mx/portal/gobierno/ped/doctos/presentacion_vision.pdf

Plan Estatal de Desarrollo de Chihuahua (2010-2016). Recuperado de http://trans parencia.chihuahua.gob.mx/atach2/Transparencia/FRACCION_VII/sf/CE_3C C_39181.pdf

Plan Estatal de Desarrollo de Coahuila (2011-2017). Recuperado de http://coahuila.gob. $\mathrm{mx} /$ archivos/pdf/Publicaciones/PED-Actualizado-280415-web.pdf

Plan Estatal de Desarrollo de Nuevo León (2010-2015). Recuperado de http://www.nl. gob.mx/sites/default/files/genl_ped_2010_2015-sinportada.pdf

Plan Estatal de Desarrollo de Sonora (2016-2021). Recuperado de http://www.sonora. gob.mx/images/documentos/p6ygfv/PED-2016-2021.pdf

Plan Estatal de Desarrollo de Tamaulipas (2011-2016). Recuperado de http://tamaulipas.gob.mx/wp-content/uploads/2013/11/PED-TAMAULIPAS-Actualizaci\%C3\% B3n-2013.pdf

Plan Nacional de Desarrollo (2013-2018). Gobierno de la República. Recuperado de http://pnd.gob.mx/

Ponce, E. (2016). La importancia de la cooperación internacional de los municipios mexicanos y la Agenda 2030. Ponencia presentada en el seminario Gobernanza en las Fronteras de México: Hacia la Agenda 2030: Dilemas para las Capacidades Institucionales Locales, El Colegio de la Frontera, México, D. F., 26 de abril.

\section{(ㅇ)(1) $(3$}


Programa de las Naciones Unidas para el Desarrollo (2016). Agenda 2030 para el Desarrollo Sostenible. Recuperado de: http://www.undp.org/content/undp/es/home/ sdgoverview/post-2015-development-agenda.html

Ramos, J. y Reyes, M. (2009). Antecedentes de un enfoque de gestión pública hacia el desarrollo en México. En J. Ramos e I. Aguilar (coords.), La gestión del desarrollo local en México: problemas y agenda (pp. 11-40). México: El Colegio de la Frontera Norte/Miguel Ángel Porrúa.

Ramos, J. M. (2002). Seguridad pública fronteriza: gestión, contexto y redefinición de políticas. Frontera Norte, 14(28), 47-81.

Ribando, C., Sullivan, M. y Beittel, J. (2009). Mexico-U.S., Relations, Issues for Congress. Congressional Research Service. U. S. Library of Congress. Washington, D. C. February. Mexico-U.S. Relations: Issues for Congress, September 10. Recuperado de http://www.ilw.com/immigrationdaily/news/2010,0503-crs.pdf Congressional Research Service 7-5700 www.crs.gov RL32724

Sanahuja, J. A., y Tezanos, S. (2016). Del milenio a la sostenibilidad: en ruta hacia la Agenda 2030 de desarrollo sostenible. Recuperado de http://www.fundacionsis tema.com/temas-253-sobre-del-milenio-a-la-sostenibilidad-la-nueva-agenda-glo bal-de-objetivos-de-desarrollo-sostenible/

Secretaría de Desarrollo Agrario, Territorial y Urbano (2014). El Programa Regional de Desarrollo del Norte 2014-2018. México: Gobierno Federal.

Secretaría de Relaciones Exteriores (2016). Diálogo Económico de Alto Nivel entre México y Estados Unidos. Declaración conjunta 2016. Recuperado de http://www.gob.mx/ sre/prensa/dialogo-economico-de-alto-nivel-entre-mexico-y-estados-unidos?stat e=published

\section{OTRAS FUENTES}

\section{Bibliografía}

Foy Valencia, P. (1998). Agenda 21. Desarrollo Sostenible: Un programa para la acción. Fondo Editorial de la Pontificia Universidad Católica del Perú. Instituto de Estudios Ambientales. Recuperado de https://books.google.com.mx/books?id= jB7XWv57IqwC\&lpg=PA14\&ots=hBrOWNujXa\&dq=importancia\%20de\%20 la\%20agenda\%2021\&hl=es\&pg=PA7\#v=onepage\&q\&f=false

General Accounting Office (julio, 1999). U.S.-Mexico Border. Issues and Challenges Confronting the United States and Mexico. Report to Congressional Requesters, Washington, D. C., p. 51.

\section{()(1) $\$$}


Oliveira, R. de (2015). Acción internacional para la sustentabilidad local. Revista Mexicana de Política Exterior, 104, 147-168.

Organización de las Naciones Unidas (2016). Objetivos de Desarrollo Sostenible. 17 objetivos para transformar nuestro mundo. Recuperado de http://www.un.org/ sustainabledevelopment/es/globalpartnerships/

Organización de las Naciones Unidas-Habitat (2006). Gobiernos locales. Grupo global post 2015. Recuperado de http://www.onuhabitat.org/index.php? option=com_content\&view=category\&layout=blog\&id=372\&Itemid=522

Organización de las Naciones Unidas Mujeres (2016). La Agenda 2030 para el Desarrollo Sostenible. Recuperado de http://www.unwomen.org/es/what-we-do/ post-2015

Prado, L. J. (2014). La cooperación internacional para el desarrollo de México. Un análisis de sus acciones, institucionalización y percepciones. Revista Mexicana de Ciencias Políticas y Sociales, LIx(222), 51- 86.

Programa de las Naciones Unidas para el Desarrollo (2016). Agenda 2030 para el Desarrollo Sostenible. Recuperado de: http://www.undp.org/content/undp/es/ home/sdgoverview/post-2015-development-agenda.html

Ramos, J. y Reyes, M., (2009). Antecedentes de un enfoque de gestión pública hacia el desarrollo en México. En J. Ramos e I. Aguilar (coords.), La gestión del desarrollo local en México: problemas y agenda (pp. 11-40). México: El Colegio de la Frontera Norte/Miguel Ángel Porrúa.

Rieznik, N. y Hernández, A. (2005). Agenda 21 Local. Madrid, España. Recuperado de http://habitat.aq.upm.es/temas/a-agenda-21.html

Secretaría de Desarrollo Económico (s. f.). Vocación industrial regional. Recuperado de http://www.investinbaja.gob.mx/es/vision/vocacion-industrial-regional

Sosa, L. J. (julio-diciembre, 2012). Formación de capacidades en los gobiernos locales en México, hacia la nueva gobernanza. Explanans, 1(2), 35-52.

United Nations Development Programme (2009) Capacity development: a UNDP PRIMER Recuperado de http://www.undp.org/content/dam/aplaws/publication/ en/publications/capacity-development/capacity-development-a-undp-primer/C DG_PrimerReport_final_web.pdf, 8 de abril 2016.

\section{()(1) $(3$}

